$B J M G 10 / 2(2007) 77-80$

$10.2478 / \mathrm{v} 10034-008-0010-4$

SHORT COMMUNICATION

\title{
WOLF-HIRSCHHORN SYNDROME: REPORT OF TWO CASES IN BOSNIA AND HERZEGOVINA
}

\author{
Heljić $\mathrm{S}^{1, *}$, Hadžagić-Ćatibušić $\mathrm{F}^{1}$, Maksić $\mathrm{H}^{1}$, \\ Terzić $\mathrm{S}^{1}$, Đozić $\mathrm{M}^{1}$, Mačkić $\mathrm{M}^{2}$, Ćatović $\mathrm{A}^{2}$
}

*Corresponding Author: Dr. Suada Heljić, Pediatric Clinic, Clinical University Center Sarajevo, Bolniča 25, 71000 Sarajevo, Bosnia and Herzegovina; Tel./Fax: +387-332-58481; E-mail: heljicsuada@hotmail.com

\begin{abstract}
Wolf-Hirschhorn syndrome (WHS) is a rare developmental disorder caused by a partial deletion of the short arm of chromosome 4 (4p-). The main phenotypic characteristics of WHS are: intrauterine growth retardation, mental retardation, typical facial dysmorphism, microcephaly and midline fusion defects (cleft lip or palate, cardiac septal defects). Other abnormalities, such as agenesis of the corpus callosum, dysplastic kidneys, iris coloboma and skeletal abnormalities have occasionally been described.

We describe two female newborn babies with a $4 p$ deletion, who have a majority of the main phenotypic features of WHS. Prenatal diagnosis of the syndrome is very important, because dysmorphologic features are associated with profound mental retardation. Postnatal recognition of the syndrome requires genetic counseling of the parents and supportive multidisciplinary treatment.
\end{abstract}

Key words: Wolf-Hirschhorn syndrome (WHS); Chromosome 4; Deletion.

Pediatric Clinic of Clinical University Center Sarajevo, 71000 Sarajevo, Bosnia and Herzegovina

2 Institut for Human Genetics Sarajevo, Medical

Faculty, University of Sarajevo, 71000 Sarajevo, Bosnia and Herzegovina

\section{INTRODUCTION}

Wolf-Hirschhorn syndrome (WHS; syndrome of deletion of distal short arm of chromosome 4) is a rare developmental disorder, first described by Cooper and Hirschhorn [1] and Wolf et al. [2]. After the first clinical description, several reports were published [3-5], but the exact incidence of the syndrome is not yet known. Shanon et al. [5] published an epidemiological study of 159 cases, estimating that the minimal incidence is 1:95896. The syndrome is characterized by developmental delay, craniofacial dysmorphism and closure defects (cleft lip or palate, heart septal defects). The common phenotype abnormalities are: microcephaly, frontal bossing, high frontal hairline, prominent glabella, hypertelorismus, ptosis, iris coloboma, wide nasal bridge, down slanting palpebral fissures, strabismus, exotropia, carplike mouth, large misshapen ears, skeleton anomalies, hypospadia and kryptorchismus. Dysmorphic features (collectively described as Greek warrior helmet facies) is frequently associated by hypotonia, seizures and reliable insensitiveness to pain [6,7]. Association with malignancy is also described [8].

Wolf-Hirschhorn syndrome is caused by a structural aberration of chromosome 4 , with deletion of 20 to $80 \%$ of its short arm. The severity of the clinical manifestations depends on the size of the deletion. Deficiency of chromosome 4 can originate from a de novo interstitial deletion (in $90 \%$ of patients) or 
derivate from parental mosaicism or unbalanced reciprocal translocation. Deletion of the terminal band (4p16.3) is essential for full expression of the phenotype [9]. Life expectancy has not been well documented, but one-third of patients die in the first year of life due to pneumonia or congestive heart faillure. Only a few patients survive into the first decade of life.

\section{CASE REPORTS}

First Case. This was the second, female, child of young and healthy parents. The family history for inborn diseases and consanguinity was negative. The first child was healthy. Intrauterine growth retardation was detected prenatally, from the $23 \mathrm{rd}$ week of

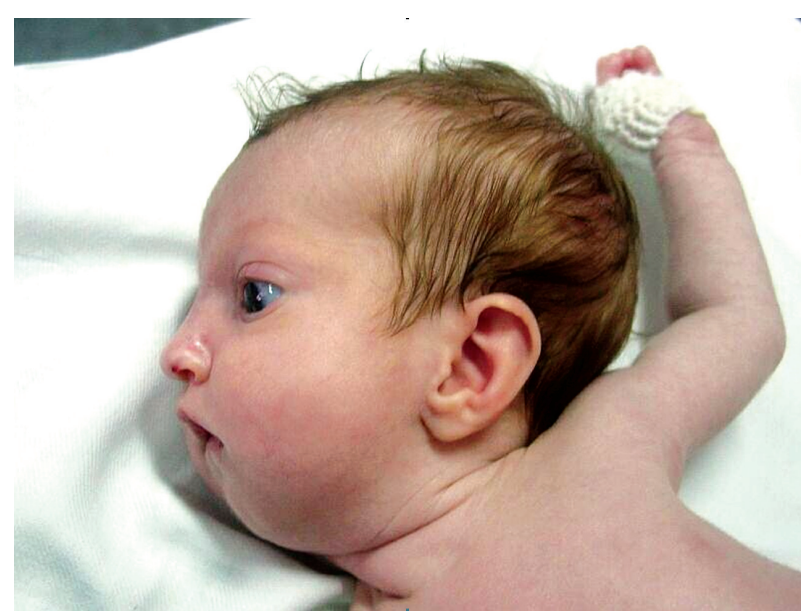

Figure 1. Characteristic dysmorphic features (Greek warrior helmet facies). gestation. The baby was born by vaginal delivery, 7 days after term, without any complications. Apgar score was $8 / 8$. Birth weight was $2.390 \mathrm{~g}(<10 \mathrm{p})$, birth length $48 \mathrm{~cm}$, head circumference $31 \mathrm{~cm}(<10 \mathrm{p})$. During hospitalization of the baby, repeated seizures, hypotonia and poor suction reflex were recorded.

The head showed microcephaly, dolichocephaly, frontal bossing, high frontal hairline, prominent glabella, hypertelorism, broad nose, down slanting palpebral fissures, exotropia, micrognathia, downturned mouth (carp like mouth), high-arched palate and large misshapen ears (Figure 1).

The trunk was relatively long and the chest was long and narrow. There were cervical spine anomalies (agenesis of bodies of vertebrae $\mathrm{C} 4$ and $\mathrm{C} 5$ ), long fingers and hypoplasia of great toes (Figure 2).

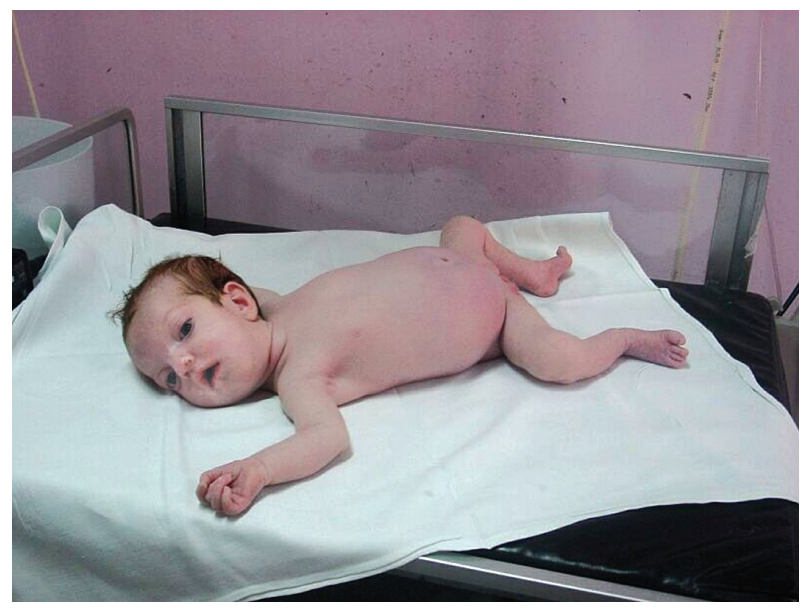

Figure 2. General appearance of patient with WHS.

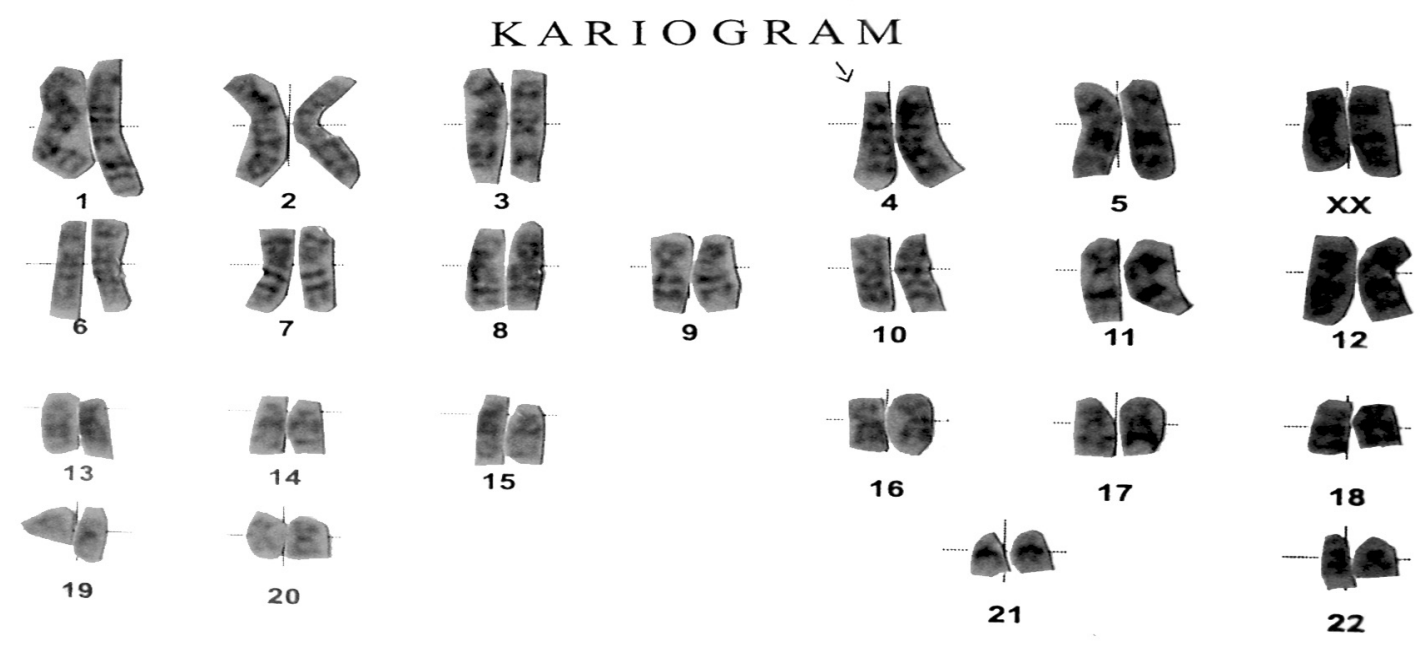

Figure 3. Cytogenetic analysis of the patient: karyotype 46;XX,del(4) (p15-p16). 
There was partial agenesis of the corpus callosum. The heart showed foramen ovale apertum, without a septal defect. There was a cyst of the right kidney. The patient was hypotonic, with feeding difficulties and clinical manifestation of seizures. The karyotype was 46;XX,del(4) (p15-p16) (Figure 3).

Second Case. This was the first female child of young parents, resulting from an uneventful pregnancy. The child was born by cesarean section, due to intrapartal asphyxia, 2 weeks after term. The birth weight was $2.200 \mathrm{~g}(<10 \mathrm{p})$, birth lenght $44 \mathrm{~cm}$ $(<10 \mathrm{p})$, head circumference $30.5 \mathrm{~cm} .(<10 \mathrm{p})$. Hypotonia and feeding difficulties were present from the beginning.

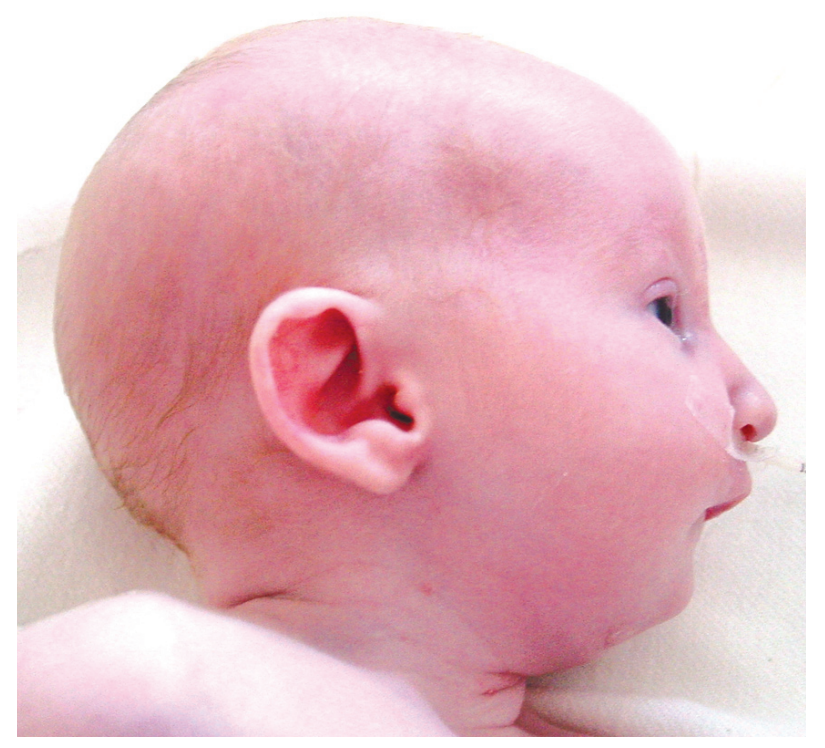

Figure 4. Typical craniofacial anomalies.

The head was dysmorhic, with a bird like face, wide nasal bridge and a broad, bent nose (Greek warrior helmet face), cleft palate, hypertelorism, micrognathia and low positioned misshapen ears (Figure 4). The fingers were long and slender, with abnormal palmar and plantar finger position. There was partial enlargement of the left lobe of the liver and spleen malrotation with the hilus pointed towards the stomach. The left kidney was dislocated and low positioned, with bilateral pyelectasia. The heart showed a $6 \mathrm{~mm}$ long atrial septal defect, with an obvious left-to-right shunt. The karyotype was $46, \mathrm{XX}$, del (4) (p15.2-p16.3)

\section{DISCUSSION}

Wolf-Hirschhorn syndrome is recognized by its clinical phenotype caused by deletion(s) in the short arm of chromosome 4 . The typical phenotype characteristics of WHS are already well known, but rarity of new cases gives the contribution to better understanding of a wide spectrum of possible clinical manifestations. Wolf-Hirschhorn syndrome has a 2:1 predilection for females. Both of the patients reported in this article are females.

Intrauterine growth retardation (IUGR) was detected in both cases. The IUGR of the first patient was detected from the $23 \mathrm{rd}$ week of gestation. According to the literature $[10,11]$, prenatal chromosomal analysis is indicated in the case of IUGR associated with other ultrasonog-raphically-detected anomalies (heart defects, hypospadia, sceletal anomalies).

Phenotype expression depends on the size of the deletion of the chromosome [12,13]. Patients with large deletions of the short arm of chromosome 4 are usually more affected, with severe developmental delay, mental retardation, microcephaly, heart defects, midline defects, kidney abnormalities and seizures. Patients with microdeletions have milder phenotypic changes, usually without congenital malformations, with milder developmental delay, although microcephaly is usually present. Patients with small microdeletions have a mild expression of the disease, which consists of typical face appearance, mild mental retardation, mild developmental delay and mild congenital hypotonia. For precise cytogenetic-morphological correlation, besides conventional chromosomal analysis, molecular probes on apparently normal chromosomes are necessary in some cases, in order to detect submicroscopic deletions $[9,12,14]$.

The facial dysmorphism of both our patients corresponds roughly to the characteristic description given by most authors $[4,5,12]$. Both patients were hypotonic, seizures were registered in the first case. Hypotonia and seizures were commonly noted by other authors $[5,9,13]$, and cytogenetic disorder was followed by hypotonia and seizures in approximately $80 \%$ of cases.

The first patient did not have a heart septal defect, but the second patient did. According to the literature, septal defects were found in half of the patients [4]. Cleft palate, described in about two-thirds of patients [9], was present in the second patient. As a part of 
midline defects, the first patient had an anomaly of the cervical spinal column and partial agenesis of the corpus callosum, anomalies which were sporadically described by other authors $[4,9]$.

\section{CONCLUSIONS}

Wolf-Hirschhorn syndrome (chromosome $4 p$ deletion syndrome) presents a broad spectrum of possible phenotypic abnormalities, followed by developmental delay and mental retardation. Because of that, any case of IUGR associated with other anomalies (heart, skeleton, kidneys), requires prenatal chromosomal analysis. Postnatal recognition of WHS requires genetic testing of the parents and multidisciplinary supportive treatment.

\section{REFERENCES}

1. Cooper H, Hirschhorn K. Apparent deletion of short arms of one chromosome (4 or 5) in a child with defects of midline fusion. Hum Chrom News 1961; 4: 14-16.

2. Wolf U, Reinwein H. Porsch R, Schröter R, Baitsch H. Deficiency of the short arms of a chromosome No. 4. Humangenetik 1965; 1(5): 397-413.

3. Thies U, Back E, Wolf G, Schroeder-Kurth T, Hager HD, Scroder K. Clinical, cytogenetic and molecular investigations in three patients with WolfHirschhorn syndrome. Clin Genet 1992; 42(4): 201-205.

4. Battaglia A, Carey JC, Cederholm P, Viskochil DH, Brothman AR, Galasso C. Natural history of Wolf-Hirschhorn Syndrome: experience with 15 cases. Pediatrics 1999; 103(4 Pt): 830-836.

5. Shanon NL, Maltby EL, Rigby AS, Quarell OWJ. An epidemiological study of Wolf-Hirschhorn syndrome. Life expectancy and cause of mortality. J
Med Genet 2001; 38(10): 674-679.

6. Žiška J. Diagnostica Syndromu a Malformaci. Praha: Galen. 1994; 245-246.

7. Matai S, Ganguly BB. Wolf- Hirschhorn (4p-) syndrome. Indian Pediatr 2003; 40(7): 681.

8. Sharathkumar A, Kirby M, Freedman M, Abdelhaleem M, Chitayat D, Teshima IE, Dror Y. Malignant hematological disorders in children with WolfHirschhorn syndrome. Am J Med Genet 2003; 119(2): 194-199.

9. Zollino M, Di Stefano C, Zampino G, Mastroiacovo P, Wright T, Sorge G, Selicorni A, Tenconi R, Zappala A, Battaglia A, Rocco M, Palka G, Pallota R, Altherr MR, Neri G. Genotype-phenotype correlations and clinical diagnostic criteria in Wolf-Horschhorn syndrome. Am J Med Genet 2000; 94(3):254-261.

10. Aslan H, Karaca N, Basaran S, Ermis H, Ceylan Y. Prenatal diagnosis of Wolf-Hirschhorn syndrome (4p-) in association with congenital hypospadias and foot deformity. BMC Pregnancy Childbirth 2003; 3 (1): 1 .

11. Tachdian G, Fondacci C, Tapia S, Huten Y, Blot P, Nessman C. The Wolf-Hirschhorn syndrome in fetuses. Clin Genet 1991; 42(6): 281-287.

12. Quarrel OWJ, Snell RG, Curtis MA, Roberts $\mathrm{SH}$, Harper PS, Shaw DJ. Paternal origin of the chromosomal deletion resulting in Wolf-Hirschhorn syndrome. J Med Genet 1991; 28(4): 256-259.

13. Wieczorek D, Krause M, Majewski F, Albrecht B, Horn D, Riess O, Gillessen-Kaesbach G. Effect of size of the deletion and clinical manifestation in WolfHirschhorn syndrme: analysis of 13 patients with a de novo deletion. Eur J Hum Genet 2000; 8(7): 519-526.

14. Finzi S, Pinto CF, Wiggs JL. Molecular and clinical characterization of a patient with a chromosome $4 p$ deletion, Wolf-Hirschhorn syndrome, and congenital glaucoma. Ophthalmic Genet 2001; 22(1): $35-41$. 